This is an electronic reprint of the original article. This reprint may differ from the original in pagination and typographic detail.

Author(s): Chen, Chengcong; Alén, Raimo; Lehto, Joni; Pakkanen, Hannu

Title: $\quad$ Combustion properties of spruce black liquor droplets : Sulfur-free pulping and influence of hot-water pretreatment

Year: $\quad 2016$

Version:

Please cite the original version:

Chen, C., Alén, R., Lehto, J., \& Pakkanen, H. (2016). Combustion properties of spruce black liquor droplets : Sulfur-free pulping and influence of hot-water pretreatment. Nordic Pulp and Paper Research Journal, 31(4), 532-540.

https://doi.org/10.3183/npprj-2016-31-04-p531-540

All material supplied via JYX is protected by copyright and other intellectual property rights, and duplication or sale of all or part of any of the repository collections is not permitted, except that material may be duplicated by you for your research use or educational purposes in electronic or print form. You must obtain permission for any other use. Electronic or print copies may not be offered, whether for sale or otherwise to anyone who is not an authorised user. 


\section{Combustion properties of spruce black liquor droplets: Sulfur-free pulping and influence of hot-water pretreatment}

\section{Chengcong Chen, Raimo Alén, Joni Lehto and Hannu Pakkanen}

KEYWORDS: Spruce; Black liquor; Combustion properties; Hot-water pretreatment; Sulfur-free pulping

SUMMARY: Hot-water pretreatment of lignocellulosics prior to sulfur-free alkaline pulping is an interesting approach for recovering value-added carbohydrate- and lignin-derived materials. This paper investigated the chemical composition variations and combustion properties of the black liquors (BLs) from three different cooking processes: two sulfur-free soda-anthraquinone (soda-AQ) and oxygen-alkali $\left(\mathrm{O}_{2}-\mathrm{NaOH}\right)$ cooks and kraft cook, before and after hot-water pretreatment of the spruce sawdust. Relatively less aliphatic acids but more lignin were present in the BLs after hot-water pretreatment as cooking time prolonged. In general, the burning time decreased as follows: soda-AQ $\mathrm{BL}>\mathrm{O}_{2-}$ $\mathrm{NaOH} \mathrm{BL} \cong \mathrm{kraft} \mathrm{BL}$. With the same cooking time, the increase in the total burning time for soda-AQ BLs compared with kraft BLs was 11-17\% (without pretreatment) and 25-39\% (with pretreatment). Compared to kraft BLs with the same cooking time, the swelling for soda-AQ and $\mathrm{O}_{2}-\mathrm{NaOH}$ BLs decreased by $8-25 \%$ and 4$23 \%$, respectively.

ADDRESSES OF THE AUTHORS: Chengcong Chen
(chengcong.chen@jyu.fi), $\quad$ Raimo Alén
(raimo.j.alen@jyu.fi), Joni Lehto (joni.t.lehto@jyu.fi), Hannu Pakkanen (hannu.k.pakkanen@jyu.fi), Laboratory of Applied Chemistry, Department of Chemistry, University of Jyväskylä, P.O. Box 35, FI40014 Jyväskylä, Finland.

\section{Corresponding author: Chengcong Chen}

The pulping process is a typical forest biorefinery process that uses wood as the raw material to produce pulp, energy, and chemical products such as turpentine, tall oil, and lignin (Grace et al. 1989; Alén 2015). However, for a number of commonly recognized reasons, modern pulp mills can serve as a promising platform for even more efficient use of raw wood materials. One motivation for developing more effective concepts is that fiber, which is suitable for versatile utilization in paper or paperboard, is already a well-established main product. One of the most interesting novel techniques is based on hot-water extraction (HWE) of feedstock prior to alkaline pulping to recover carbohydrate-derived fragments that can be converted into value-added chemicals and other bioproducts (Wayman, Chua 1979; Mosier et al. 2005; Kamm et al. 2006; van Heiningen 2006; Carvalheiro et al. 2008; Yoon et al. 2008; Alén 2011; Lehto 2015).

Combustion of black liquor (BL) from alkaline pulping plays a key role in supplying energy and recovering inorganic cooking chemicals for the fiber refinery system. BL is combusted as sprayed droplets, undergoing three sequential stages: drying, pyrolysis, and char burning, and exhibits volumetric swelling, which influence the performance of the recovery boiler in terms of deposition in the upper furnace and condition of the char bed (Frederick, Hupa 1997). In our previous study (Chen et al. 2016), the combustion properties of birch black liquors (BLs) based on sulfur-free soda-AQ and $\mathrm{O}_{2-}$ $\mathrm{NaOH}$ cooks with and without the feedstock HWE were investigated. It was found that sulfur-free BLs swell less than kraft BLs, and hot-water pretreatment of feedstock result in lower swelling for kraft and soda-AQ liquors but higher swelling for $\mathrm{O}_{2}-\mathrm{NaOH}$ liquors. However, the information available in the literature on the combustion properties of sulfur-free softwood BLs is very limited.

This work was undertaken to compare the combustion properties of kraft BL with those of spruce BLs from sulfur-free soda-AQ and $\mathrm{O}_{2}-\mathrm{NaOH}$ cooks. In all cases, the cooking experiments were performed with both the untreated and HWE feedstocks. To obtain variations in the pretreatment stage, the treatment phase was made both as a batch (followed by the soda-AQ cook) and a continuous (followed by the $\mathrm{O}_{2}-\mathrm{NaOH}$ cook) process. Combustion tests were carried out with single $\mathrm{BL}$ droplets at $800^{\circ} \mathrm{C}$ in stagnant air.

\section{Materials and Methods}

\section{Sawdust materials}

Raw Norway spruce (Picea abies) sawdust ( $<5 \mathrm{~mm}$ ) was provided by the Finnish Forest Research Institute (Metla). The HWE of sawdust was conducted in two different methods: a batch process and a continuous process. The yields after the treatment were $80.0 \%$ and $75.5 \%$, respectively. Chemical composition of untreated and treated raw materials subjected to pulping are given in Table 1.

In the batch process, the pressurized HWE of non-dried sawdust was performed using a pilot-scale batch system (VTT Technical Research Center of Finland Ltd., Espoo, Finland). The extraction liquid (i.e., hot water) was circulated during the extraction which was performed in two stages (liquor-to-wood ratio in both stages was $5 \mathrm{l} / \mathrm{kg}$ ): the first stage at $160^{\circ} \mathrm{C}$ for $40 \mathrm{~min}$ (P-factor $\sim 181$, Tunc and van Heiningen 2009) and the second stage at $170^{\circ} \mathrm{C}$ for $60 \mathrm{~min}$ (P-factor $\sim 597$ and the combined Pfactor $\sim 780$ ). Between these two stages, the hydrolysate was drained from the reactor as completely as possible. After both extraction steps, the extracted material was washed with water $\left(50^{\circ} \mathrm{C}\right.$, liquor-to-wood ratio was $51 / \mathrm{kg}$ ) for $30 \mathrm{~min}$ and removed from the reactor.

In the continuous process, the HWE of non-dried sawdust was performed with a pilot-scale flow through extraction reactor (Viitos-Metalli Ltd., Heinola, Finland). During extraction, spruce sawdust was treated for $\sim 32 \mathrm{~min}$ at $180^{\circ} \mathrm{C}$, and the corresponding P-factor was $\sim 680$. After the treatment, the sawdust was immediately removed from the reactor without being washed.

The untreated and treated sawdust samples were stored in a freezer at $-18^{\circ} \mathrm{C}$. The moisture content of feedstock 
was determined according to the TAPPI Test Method 264 $\mathrm{cm}-97$ in an oven at $105^{\circ} \mathrm{C}$. In all wet chemistry analyses for compositional determination (i.e., carbohydrates, lignin, and extractives), the results were an average of two parallel determinations and calculated as percentage of dry sample.

\section{Pulping experiments}

Soda-AQ, $\mathrm{O}_{2}-\mathrm{NaOH}$, and kraft BLs were prepared by pulping both the untreated and HWE sawdust in 1.25-liter rotating stainless steel autoclaves heated in an oil bath (CRS Autoclave System 420, from CRS Reactor Engineering $\mathrm{AB}$, Stenkullen, Sweden). In the $\mathrm{O}_{2}-\mathrm{NaOH}$ pulping, pure oxygen was bubbled through the cooking liquor for $5 \mathrm{~min}$ prior to charging sawdust into the reactors. Then, the reactors were closed and purged with oxygen through the lid for two minutes to ensure an oxygen atmosphere. The specific pulping conditions are given in Table 2. Pulp yields were calculated on the oven dry basis of the initial feedstock (Table 3).

\section{Analyses of sawdust}

The extractives content was determined according to the TAPPI Test Method T280 pm-99 by extracting the sample with acetone in a Soxhlet apparatus (extraction time $4 \mathrm{~h}, 6$ to 10 percolations per hour). The obtained extract was concentrated using vacuum evaporation with a rotary evaporator (Heidolph VV2000, from Gemini BV Laboratory, Apeldoorn, the Netherlands), exposed to a nitrogen gas stream until it was dried, and finally weighed. The lignin content of the extractive-free sawdust sample was determined as the sum of "acidinsoluble Klason lignin" and "acid-soluble lignin" (TAPPI Test Methods T222 om-98 and T249 cm-00). In this determination, sawdust was first treated with $72 \%$ $\mathrm{H}_{2} \mathrm{SO}_{4}$ followed by an autoclave treatment after dilution, and the precipitated Klason lignin was filtered off (degraded carbohydrates remained in the hydrolysate), washed, dried, and weighed. The acid-soluble lignin content was determined using a Beckman DU 640 UV/Vis-spectrophotometer (Beckman Instruments Inc., Fullerton, CA, USA) at $205 \mathrm{~nm}$ (to avoid the interfering influence of furans at $280 \mathrm{~nm}$ ) after diluting one portion of hydrolysate with a corresponding aqueous solution of $\mathrm{H}_{2} \mathrm{SO}_{4}(0.5 \%)$ until the absorbance $(A)$ was in the 0.3 to 0.8 range.

Table 1 - Chemical composition of feedstock materials (\% of the dry solids).

\begin{tabular}{lccc}
\multicolumn{1}{c}{ Component } & Ref & HWE-B & HWE-C \\
\hline Carbohydrates ${ }^{\text {a }}$ & 60.0 & 60.4 & 65.7 \\
Arabinose & 1.0 & $<0.1$ & 0.1 \\
Galactose & 1.8 & 0.4 & 0.5 \\
Glucose & 41.1 & 51.6 & 57.2 \\
Mannose & 11.1 & 4.8 & 4.0 \\
Xylose & 5.0 & 3.7 & 3.9 \\
Lignin & 28.4 & 35.2 & 30.1 \\
Klason & 28.0 & 34.9 & 29.8 \\
Acid-soluble & 0.4 & 0.3 & 0.3 \\
Acetone-soluble materials & 1.4 & 2.6 & 1.0 \\
Others & 10.1 & 1.8 & 3.2 \\
\hline
\end{tabular}

Ref: untreated feedstock.

HWE-B: Hot-water extracted feedstock using a batch process by VTT.

HWE-C: Hot-water extracted feedstock using a continuous process by Metla.

a Monosaccharide moieties are presented as their anhydro forms

Table 2 - Cooking data.

\begin{tabular}{lccc}
\hline \multicolumn{1}{c}{ Parameter } & Soda-AQ & $\mathbf{O}_{2}-\mathrm{NaOH}$ & Kraft \\
\hline Effective alkali, $\%$ & 20 & 19 & 19 \\
Sulfidity, $\%$ & - & - & 35 \\
Anthraquinone, $\%$ & 0.1 & - & - \\
Oxygen bubbled, min & - & 5 & - \\
Liquor-to-wood ratio, $1 / \mathrm{kg}$ & 5 & 5 & 5 \\
Maximum temperature, ${ }^{\circ} \mathrm{C}$ & 170 & 170 & 160 \\
Cooking time, min & $30,60,90,120$, and 150 & $30,60,90,120$, and 150 & $30,60,90,120$, and 150 \\
\hline
\end{tabular}

Table 3 - Pulp yields ${ }^{a}$ of different cooks. For abbreviations, see Tables 1 and 2.

\begin{tabular}{crrrrrr}
\hline \multirow{2}{*}{ Cooking time, $\min$} & \multicolumn{2}{c}{ Soda-AQ } & \multicolumn{2}{c}{ O2-NaOH $_{2}$ (Lehto 2015) } & \multicolumn{2}{c}{ Kraft } \\
& Ref & HWE-B & Ref & HWE-C & Ref & HWE-B \\
\hline 30 & 60.2 & 48.8 & 67.9 & 56.2 & 63.3 & 48.2 \\
60 & 53.7 & 43.2 & 65.3 & 53.1 & 57.7 & 44.8 \\
90 & 49.9 & 39.6 & 60.3 & 50.1 & 54.3 & 41.1 \\
120 & 50.4 & 38.0 & 58.3 & 48.2 & 52.5 & 44.1 \\
150 & 48.4 & 36.2 & 57.4 & 46.3 & 51.8 & 38.1 \\
\hline
\end{tabular}

a Pulp yields (\%) are based on the initial o.d. feedstock. 
The concentration of dissolved lignin $c(\mathrm{~g} / \mathrm{l})$ was calculated according to the Beer-Lambert equation ( $E q$ 1).

$$
c=A / a b,
$$

where $a$ is absorptivity (120 $\mathrm{l} /(\mathrm{g} \bullet \mathrm{cm})$, Swan 1965), and $b$ is the light path length $(\mathrm{cm})$.

The carbohydrates presented as different monosaccharide moieties (i.e., arabinose, galactose, glucose, mannose, and xylose) in the Klason hydrolysates were determined with a Hewlett Packard 5890 Series II Plus GC gas chromatography system equipped with an Agilent DB-1701 column $(60 \mathrm{~m} \times 0.32 \mathrm{~mm}$ inner diameter, film thickness $0.25 \mu \mathrm{m}$ ) and a flame-ionization detector (GC/FID) operated at $300^{\circ} \mathrm{C}$. The column temperature program was $2 \mathrm{~min}$ at $100^{\circ} \mathrm{C}, 2^{\circ} \mathrm{C} / \mathrm{min}$ to $185^{\circ} \mathrm{C}$ (for $27 \mathrm{~min}$ ), $39^{\circ} \mathrm{C} / \mathrm{min}$ to $280^{\circ} \mathrm{C}$, and finally $15 \mathrm{~min}$ at $280^{\circ} \mathrm{C}$. For GC/FID, a liquor sample of $10 \mathrm{~mL}$ was neutralized with anion exchange resin (Amberlite IRA68, Alfa Aesar, Karlsruhe, Germany) until the hydrolysate $\mathrm{pH}$ value was approximately 4 . The resin was filtered off, and $1 \mathrm{~mL}$ of an aqueous (i.e., ultra-high quality water (UHQ) obtained from a Milli-Q Plus water system; Millipore, Bedford, MA, USA) mixture of an internal standard (ISTD, xylitol, $0.25 \mathrm{mg} / \mathrm{mL}$; Fluka Chemical Corporation, Seeltze, Germany) was added to the filtrate, and the sample was evaporated to complete dryness using a vacuum evaporator. Finally, the residue was per(trimethylsilyl)ated by adding $1.25 \mathrm{~mL}$ pyridine (Fluka Chemical Corporation, Seeltze, Germany) and $0.75 \mathrm{~mL} \quad \mathrm{~N}, \mathrm{O}$-bis(trimethylsilyl)trifluoroacetamide (BSTFA, Regis Technologies, Morton Grove, IL, USA) containing $1 \%$ trimethylchlorosilane (TMCS, Regis Technologies, Morton Grove, IL, USA), and the mixture was shaken for approximately $60 \mathrm{~min}$ at room temperature. The samples were filtrated to sample vials and analyzed using GC. Peak identification and massbased response factors between the ISTD and each monosaccharide were based on separate runs with model monosaccharides (Fluka Chemical Corporation, Seeltze, Germany).

\section{Analyses of BLs}

Determination of dry BL solids was conducted based on the TAPPI Test Methods T650 om-09.

Formic and acetic acids (later referred to as "volatile acids"), which were in their sodium salt forms under alkaline conditions, were determined as their benzyl esters using gas chromatography equipped with a flameionization detector (GC/FID) (Alén et al. 1985). In this analysis, these acids in liquor samples were first converted to their tetra- $n$-butylammonium salts, and then benzyl esters of these salts were prepared and introduced to the GC/FID system.

Aliphatic hydroxy carboxylic acids were separated as their per(trimethylsilyl)ated derivatives using GC/FID, and the same derivatives were identified using gas chromatography equipped with a mass-selective detector GC/MSD (Alén et al. 1984). This method involved the conversion of these acids first into their ammonium salts that were then per(trimethylsilyl)ated with BSTFA containing $1 \%$ TMCS.
The content of dissolved lignin in BLs was determined using UV/Vis-spectrophotometry at $280 \mathrm{~nm}$ (Alén, Hartus 1988). In this determination, the samples were diluted with $0.1 \mathrm{M} \mathrm{NaOH}$ until the absorbance was in the 0.3 to 0.8 range. The content of dissolved lignin was calculated according to the Beer-Lambert equation $(E q 1)$; the absorptivity values used were $22.8,17.1$, and $20.3 \mathrm{l} /(\mathrm{gcm})$ for soda-AQ, $\mathrm{O}_{2}-\mathrm{NaOH}$, and kraft lignins, respectively.

A size exclusion chromatographic system (a Waters HPLC system equipped with a column filled with Superdex 75 gel using $0.1 \mathrm{M}$ aqueous $\mathrm{NaOH}$ as the eluent) was applied to determine the molar mass (MM) distribution of dissolved lignin in BL (Pakkanen, Alén 2012). For these analyses, the BLs were diluted with the $\mathrm{NaOH}$ eluent to achieve a dilution ratio of $1 / 20$.

\section{Combustion tests}

Combustion tests were carried out using a laboratory furnace at the University of Jyväskylä. The furnace is equipped with a glass window from aside for observing the combustion process using a video camera, a hole from the top for insertion of BL droplet using a glass rod with a platinum hook, and a small opening for air inlet. BLs were concentrated to a dry solids content of $55-65 \%$ via evaporation under reduced pressure at $40^{\circ} \mathrm{C}$. In each test, 15 to 20 individual $\mathrm{BL}$ droplets approximately $9 \mathrm{mg}$ in wet mass were burnt at $800^{\circ} \mathrm{C}$ in stagnant air, as described in Louhelainen (2003). The progression of droplet combustion was recorded using a high resolution video camera. The pyrolysis and char burning time of the BL dry solids ( $\mathrm{s} / \mathrm{mg}$ ) was obtained from the video with the assistance of the VirtualDub software. The maximum specific swelling of each droplet $S_{\max }\left(\mathrm{cm}^{3} / \mathrm{g}\right)$ was calculated by approximating swollen particles as ideal spheres $(E q 2)$.

$$
S_{\max }=\frac{4}{3} A \sqrt{\frac{A}{\pi}} / m
$$

where $A$ is the cross sectional area of a swollen particle measured using the ImageJ software at the point of maximum swelling as observed in a selected frame of video recording, and $m$ is the dry mass of a droplet.

\section{Results and discussion}

\section{Feedstock materials and delignification}

The chemical composition of sawdust samples before and after hot-water treatment is presented in Table 1. The yields of the batch (sample HWE-B) and continuous (sample HWE-C) extraction were similar: $80.0 \%$ and $75.5 \%$ of the o.d. raw material, respectively. In both cases, approximately $70 \%$ of the hemicellulose-derived materials (i.e., the hemicellulose monosaccharide moieties arabinose, galactose, glucose (only partly in hemicelluloses), mannose, and xylose), besides acetic acid from the partial deacetylation of glucomannans (Alén 2011; Lehto 2015), were removed from the initial feedstock. Therefore, due to this primary effect, the relative proportions of glucose (mostly incorporated in cellulosic fiber) and lignin were slightly increased. 
The principal purpose of this investigation was to study the effects of hot-water pretreatment on the combustion properties of BLs. The approach was to prepare and test BLs with varying compositions rather than to clarify in detail, for example, the influence of cooking parameters on delignification. The cooking data and pulp yields are shown in Tables 2 and 3. In general, it can be noted that the pretreatment stage significantly facilitated the cooking performance. This trend was clear because the pretreatment rendered the feedstock more accessible to cooking chemicals and also caused the cleavage of major lignin-hemicellulose bonds (Lehto 2015).

\section{BL composition}

The concentration of aliphatic carboxylic acids (volatile acids and hydroxy acids) and lignin in BLs obtained from different cooking methods of the untreated and HWE sawdust is presented in Fig 1 shows the relative composition of these substances. The primary difference between various BLs was the content of aliphatic acids. The difference was attributed to deacetylation of glucomannans during the pretreatment stage resulting in a lower concentration of acetic acid in BLs from the HWE feedstocks than those from the untreated sawdust. In contrast, the changes in concentrations of another volatile acid, formic acid, were not significant because this acid was obtained from carbohydrates via peeling reactions (Alén 2000). Thus, its formation rate was similar to that of hydroxy acids.

The results indicated that in all cases the formation of hydroxy acids was slightly more intense from the HWE sawdust than from the untreated sawdust (Table S2). This phenomenon could be primarily explained by the partial removal of acetyl groups during the pretreatment stage; thus, less alkali was needed to neutralize acetic acid in the cooking stage, and more alkali (i.e., higher alkalinity)
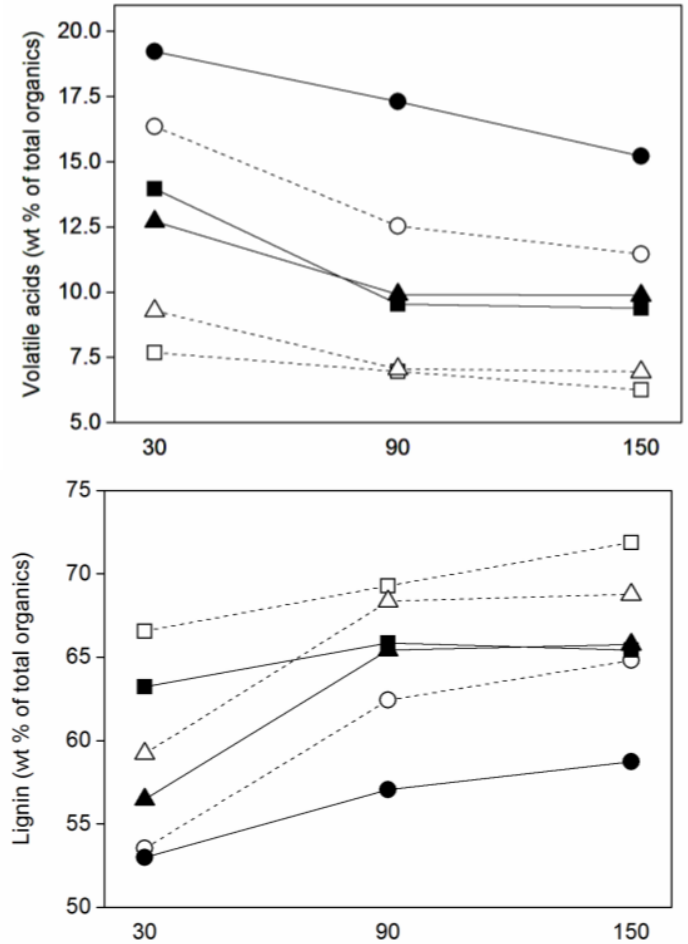

was available for various alkaline degradation reactions of polysaccharides leading to a more pronounced degradation of hemicelluloses and cellulose (Alén 2000). HWE causes acid hydrolysis, giving rise to new reducing end groups that are prone to peeling reactions in the alkaline cooking. Another clear reason was a more effective diffusion of the cooking chemicals into the wood matrix due to partial removal of the acetyl groups (Sjöström et al. 1965). Furthermore, the pretreatment stage and prolonged cooking time seemed to promote the formation of hydroxy acids (10-35\%) in the soda-AQ and kraft pulping. However, there were no significant differences in the formation of individual acids. One minor exception was, for example, the increased amount of xyloisosaccharinic acid in the BL from the HWE feedstocks.

In general, the concentration of lignin was higher in the BLs from the HWE feedstocks compared with those from the untreated feedstock (Table S2). As expected from the pulp yield data in Table 3, the lignin concentration in the $\mathrm{O}_{2}-\mathrm{NaOH} \mathrm{BL}$ was clearly at a lower level than that in the soda-AQ and kraft BLs. It was shown that the cooks performed with the HWE feedstocks resulted in higher MM fractions (Fig 2). Furthermore, the weight average $\mathrm{MM}$ of dissolved lignin in the BLs from the HWE feedstocks was the highest in the soda-AQ BLs (Table 4).

Fig 2 shows the examples of MM distributions of lignin in different BLs. Additionally, these data clearly suggested that the higher-MM fraction (> $5000 \mathrm{~g} / \mathrm{mol}$ ) of lignin was somewhat pronounced in BLs from the HWE feedstocks than that in BLs from the untreated BLs. In addition, especially for the $\mathrm{O}_{2}-\mathrm{NaOH}$ and kraft BLs, the prolonged cooking times resulted in more high-MM dissolved lignin.
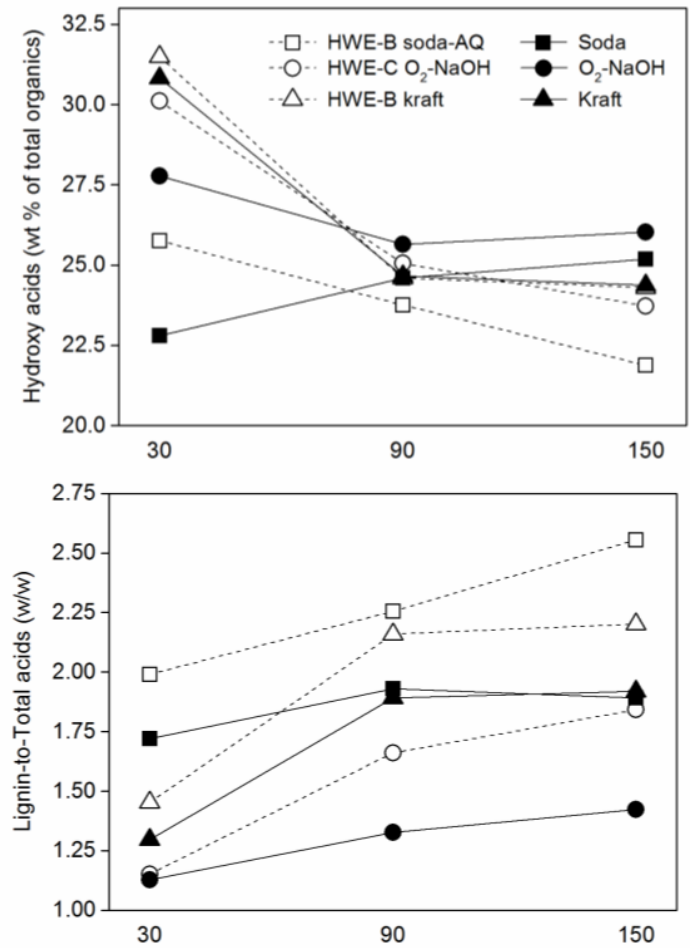

Fig 1- Comparison of the main organic composition of BLs. HWE-B and HWE-C refer to hot-water extractions of feedstock (see Table 1). 30,90 , and 150 are cooking times ( $\min )$ 
Table 4 - Weight average MM ( $\mathrm{g} / \mathrm{mol})$ of lignin in BLs. For abbreviations, see Tables 1 and 2.

\begin{tabular}{crrrrrl}
\hline $\begin{array}{c}\text { Cooking time } \\
(\mathbf{m i n})\end{array}$ & \multicolumn{2}{c}{ Soda-AQ } & \multicolumn{2}{c}{ O $_{2}$-NaOH } & \multicolumn{2}{c}{ Kraft } \\
Ref & HWE-B & Ref & HWE-C & Ref & HWE-B \\
\hline 30 & 6080 & 7340 & 5410 & 6160 & 5310 & 6770 \\
60 & 6150 & 7520 & 5940 & 6770 & 4840 & 6340 \\
90 & 6070 & 7200 & 6340 & 7130 & 6290 & 6900 \\
120 & 5920 & 6830 & 6440 & 7450 & 5360 & 7220 \\
150 & 5560 & 7080 & 6290 & 7420 & 5180 & 6960 \\
\hline
\end{tabular}
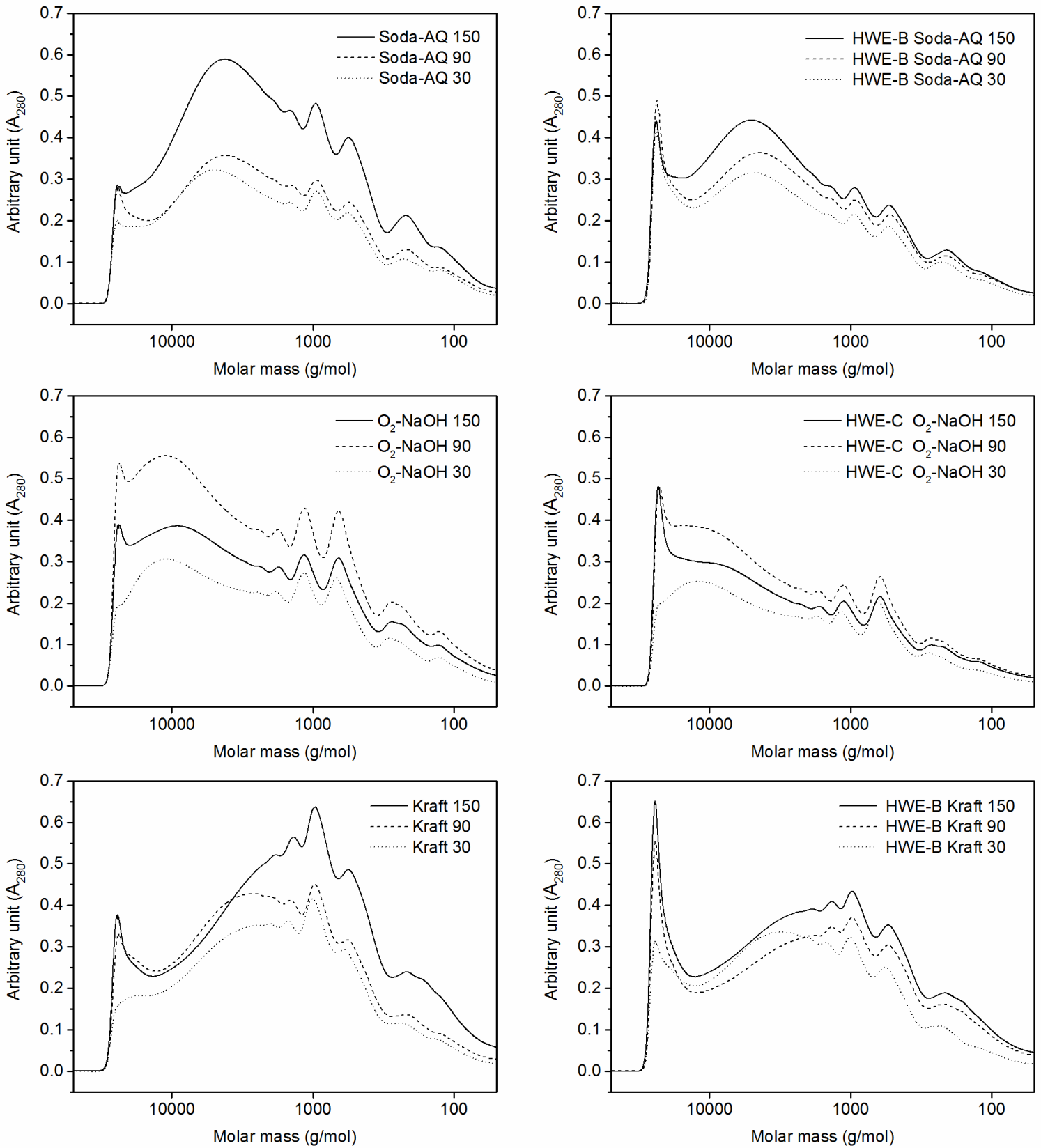

Fig 2 - Molar mass distribution of lignin. HWE-B and HWE-C refer to hot-water extractions of feedstock (see Table 1). 30, 90, and 150 are cooking times $(\mathrm{min})$.

In all BLs, of the main organic compound groups, dissolved lignin corresponded to the highest relative proportion, and volatile acids represented the lowest one (Fig 1). These values may have an interesting role in the combustion properties of BL (Noopila et al. 1991; Alén et al. 1992; Alén 1997, 2000;). For example, higher mass ratios of lignin-to-total acids (1.2-2.6 vs. 1.1-1.9) were observed for the BLs from HWE feedstocks. It should be noted that $\mathrm{O}_{2}-\mathrm{NaOH}$ BLs had clearly lower corresponding ratios (1.1-1.8) than those for other BLs (1.3-2.6). 

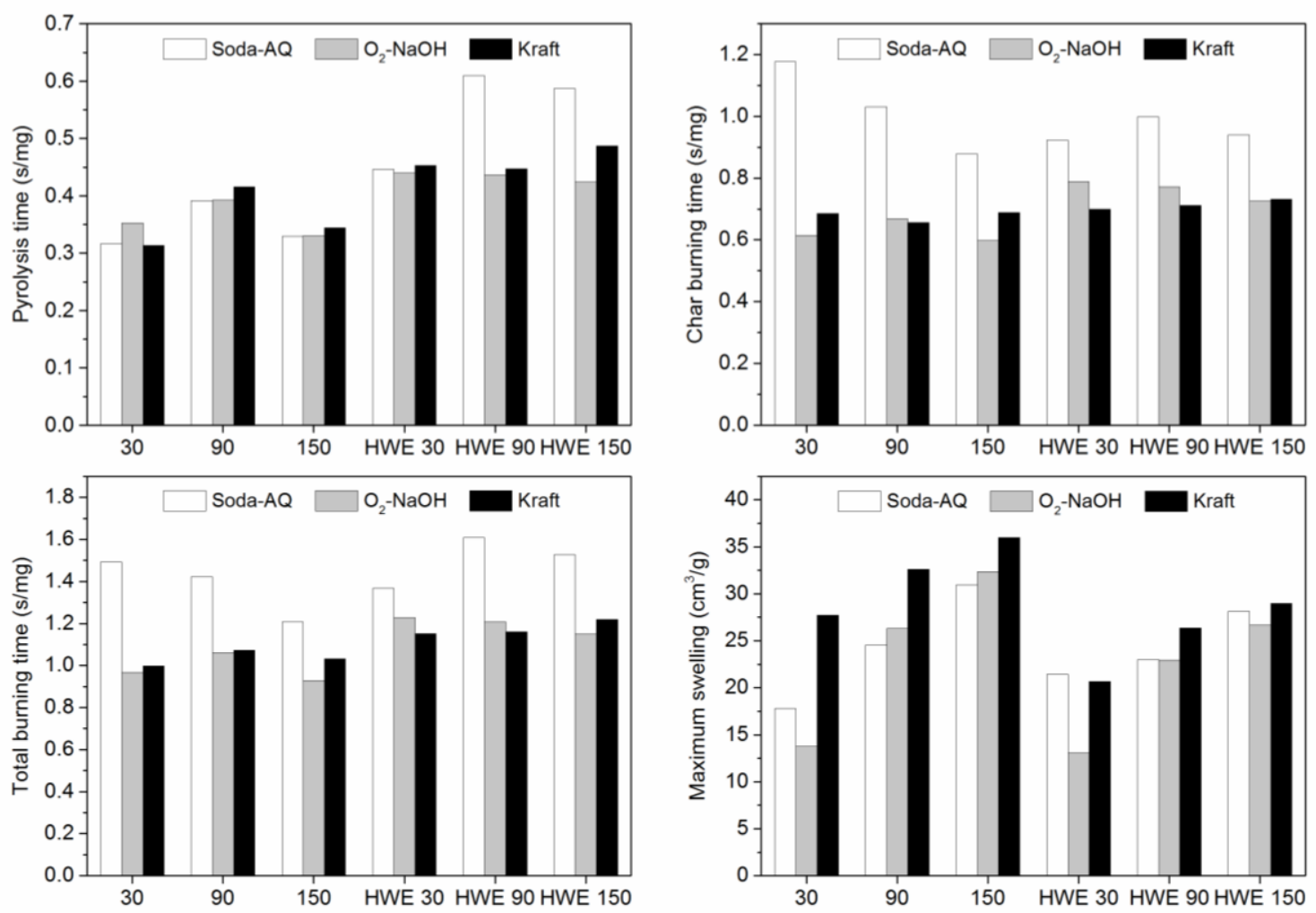

Fig 3 - Combustion properties of BLs. HWE refers to hot-water extractions of feedstock (see Table 1). 30, 90, and 150 are cooking times (min).

\section{Combustion properties of BLs}

Fig 3 illustrates the pyrolysis time, char burning time, and total burning time (i.e., pyrolysis time plus char burning time) as well as specific maximum swelling of the studied BLs. Based on the earlier research (Alén, 2000, Alén 2011), variations in the chemical composition of BL were expected to be characteristically reflected on the combustion properties of BL. First, aliphatic organics (i.e., organic acids and hemicellulose residues are relatively unstable upon heating) release significant amounts of volatile compounds that are important, especially in the pyrolysis phase and swelling of BL droplets. Second, aromatic organics (i.e., lignin is relatively stable upon heating) influence the char burning phase and determine the purity of carbon (residual char skeleton) necessary to reduce sodium sulfate to be recovered as sodium sulfide. In addition, it has been suggested that the average MM of dissolved lignin is an important factor for swelling.

In our experiments, the straightforward interpretation of combustion results based only on variations in the relative proportions of main organic compound groups of BLs showed to be somewhat difficult. However, except for BLs from an early cooking time of $30 \mathrm{~min}$, the pyrolysis time and to some extent the char burning time decreased for the BLs from the untreated feedstock with an increase in cooking time (Fig 3). Furthermore, it was noted that BLs from the soda-AQ cooks from the pretreated feedstocks clearly had longer pyrolysis times than those from other cooking methods; for example, with the same cooking time, $4-36 \%$ higher than those for the kraft BLs. In general, the BLs from pretreated feedstocks have a longer pyrolysis time and char burning time than those from the untreated feedstock; with the same cooking time, the increase in pyrolysis time for the soda-AQ BLs was $7-45 \%$, for the $\mathrm{O}_{2}-\mathrm{NaOH}$ BLs $5-28 \%$, and for the kraft BLs 7-45\%.

It should be further noted that the lignin-to-total acids mass ratio (Fig 1 and Table Sl) typically increased along with delignification, and for each cooking time, this ratio was also higher for BLs from the HWE feedstocks than those from the untreated feedstocks. In addition, the average MM of lignin was higher in the BLs from HWE feedstocks than in the corresponding BLs from the untreated feedstock. This seemed to have resulted in longer burning times. For example, both the pyrolysis time and total burning time were higher for BLs from pretreated feedstocks. The char burning times for sodaAQ BLs from pretreated feedstocks were 33-41\% higher than those for the corresponding kraft BLs with the same cooking time.

In summary, the total burning time of BLs for both the untreated and pretreated feedstocks was shown to decrease as follows: soda-AQ BL $>\mathrm{O}_{2}-\mathrm{NaOH} \mathrm{BL}>\mathrm{kraft}$ BL. In addition, with the same cooking time, compared to the corresponding kraft BLs, higher total burning times were noted for BLs from pretreated feedstocks than those from the untreated BLs; for the soda-AQ BLs 1-27\%, for the $\mathrm{O}_{2}-\mathrm{NaOH}$ BLs 3-24\%, and for the kraft BLs 6-19\%. This parameter was also similar to that detected for the corresponding birch BLs (Chen et al. 2016). In general, char burning times were clearly higher for the sulfur-free BLs than for the corresponding kraft BLs.

The swelling occurring simultaneously in the pyrolysis stage is a significant parameter in the combustion of BL droplets. Swelling is mainly a result of the interaction 
between lignin and aliphatic acids, which is also affected by other liquor compositions (e.g., polysaccharides, extractives, and inorganics) and furnace conditions (e.g., temperature, pressure, and atmosphere) (Hupa et al. 1987; Milanova 1988; Frederick et al. 1991; Noopila et al. 1991; Alén et al. 1992; Frederick, Hupa 1994; Alén 1997, 2000; Whitty et al. 1997, Whitty et al. 2008; Maček 1999). In our experiments, the maximum swelling was observed near the end of pyrolysis stage, and swelling increased with an increase in cooking time (Fig 3). It could be concluded that the amount of dissolved lignin and particularly the higher-MM fraction of lignin play an important role in hindering the escape of volatile products from aliphatic constituents within a BL droplet. The BLs from pretreated feedstocks swelled less than those from the untreated feedstock: with the same cooking time, a decrease of $2-11 \%, 5-18 \%$, and $12-26 \%$ for the soda-AQ, $\mathrm{O}_{2}-\mathrm{NaOH}$, and kraft BLs, respectively. Furthermore, the soda-AQ and $\mathrm{O}_{2}-\mathrm{NaOH}$ BLs (from the untreated feedstock) swelled less than the corresponding kraft BLs (8-25\% and $4-23 \%$, respectively). In general, a similar level of swelling was obtained for the corresponding birch BLs (Chen et al. 2016), while the most significant swelling occurs for the kraft BLs.

\section{Conclusions}

The hot-water pretreatment of the feedstock prior to alkaline pulping resulted in a varied chemical composition of the BLs and thus, their combustion properties. New data on the combustion properties of sulfur-free spruce BLs from soda-AQ (with pretreatment) and $\mathrm{O}_{2}-\mathrm{NaOH}$ pulping are shown. Soda-AQ BLs were higher in char burning time (and total burning time) than the $\mathrm{O}_{2}-\mathrm{NaOH}$ and kraft $\mathrm{BLs} ; \mathrm{O}_{2}-\mathrm{NaOH}$ BLs behaved similarly to the reference kraft BLs in burning times; sulfur-free BLs were generally lower in swelling than the kraft BLs, especially for those without HWE. In addition, the pretreatment generally increased the total burning time and decreased the swelling of BLs.

\section{Acknowledgements}

Financial support from the Academy of Finland (to Chengcong Chen) within the framework of the International Doctoral Programme in Bioproducts Technology (PaPSaT) and Maj and Tor Nessling Foundation (to Joni Lehto) is gratefully acknowledged. Marjatta Kleen from the VTT Technical Research Centre of Finland Ltd and Olli Byman and Petri Kilpeläinen from the Natural Resources Institute Finland (Luke) (formerly the Finnish Forest Research Institute, Metla) are also gratefully acknowledged for kindly providing feedstock materials for the cooking experiments. Special thanks are due to Marja Salo for her skilful assistance with the analyses of aliphatic carboxylic acids.

\section{Literature}

Alén, R. (1997): Analysis of degradation products: A new approach to characterizing the combustion properties of kraft black liquors, J. Pulp Paper Sci., 23(2), 62-66

Alén, R. (2000): Basic chemistry of wood delignification, In: Stenius, P. (ed.) Forest Products Chemistry, Fapet Oy, Helsinki, Finland, pp. 58-104.
Alén, R. (2011): Principles of biorefining, In: Alén, R. (ed.), Biorefining of Forest Resources, Paper Engineers' Association, Helsinki, Finland, pp. 55-114.

Alén, R. (2015): Pulp mills and wood-based biorefineries, In: Pandey, A., Höfer, R., Taherzadeh, M., Nampoothiri, K.M. and Larroche, C. (eds.) Industrial Biorefineries \& White Biotechnology, Elsevier, Amsterdam, the Netherlands, pp. 91126.

Alén, R. and Hartus, T. (1988): UV spectrophotometric determination of lignin from alkaline pulping liquors, Cellul. Chem. Technol., 22(6), 613-618.

Alén, R., Hupa, M. and Noopila, T. (1992): Combustion properties of organic constituents of kraft black liquors, Holzforschung, 46(4), 337-342.

Alén, R., Jännäri, P. and Sjöström, E. (1985): Gas-liquid chromatographic determination of volatile fatty acids $\mathrm{C}_{1}-\mathrm{C}_{6}$, and lactic acid as their benzyl-esters on a fused-silica capillary column, Finn. Chem. Lett., 12, 190-192.

Alén, R., Niemelä, K. and Sjöström, E. (1984): Gas-liquid chromatographic separation of hydroxy monocarboxylic acids and dicarboxylic acids on a fused-silica capillary column, J. Chromatogr. A, 301, 273-276.

Carvalheiro, F., Duarte, L.C. and Gírio, F.M. (2008): Hemicellulose biorefineries: a review on biomass pretreatments J. Sci. Ind. Res., 67, 849-864.

Chen, C., Alén, R., Lehto, J. and Pakkanen, H. (2016): Combustion properties of black liquors from sulfur-free pulping of birch sawdust, J. Wood Chem. Technol., 36, 401-411

Frederick, W.J. and Hupa, M. (1997): Black liquor droplet burning processes, In: Adams, T.N. (ed.) Kraft Recovery Boilers, TAPPI PRESS, Atlanta, GA, USA, pp.129-160.

Frederick, W.J. and Hupa, M. (1994): The effects of temperature and gas composition on swelling of black liquor droplets during devolatilization, J. Pulp Paper Sci., 20(10), 274280.

Frederick, W.J., Noopila, T. and Hupa, M. (1991): Swelling of spent pulping liquor droplets during combustion, J. Pulp Paper Sci., 17(5), 164-170.

Grace, T.M., Leopold, B., Malcom, E.W. and Kocurek, M.J. (Eds.) (1989): Pulp and Paper Manufacture, Vol. 5, Alkaline Pulping, 3rd ed., The Joint Textbook Committee of the Paper Industry, TAPPI\&CPPA, USA and Canada.

Hupa, M., Solin, P. and Hyöty, P. (1987): Combustion behaviour of black liquor droplets, J. Pulp Paper Sci., 13(2), 6772 .

Kamm, B., Kamm, M., Gruber, P.R. and Kromus, S. (2006): Biorefinery systems - An overview, In: Kamm, B., Gruber, P.R. and Kamm, M. (Eds.) Biorefineries - Industrial Processes and Products, Status Quo and Future Directions, Vol. 1, Wiley-VCH, Weinheim, Germany, pp. 3-40.

Lehto, J. (2015): Advanced Biorefinery Concepts Integrated to Chemical Pulping, Ph.D. Thesis, Laboratory of Applied Chemistry, University of Jyväskylä, Jyväskylä, Finland.

Louhelainen, J. (2003): Changes in the Chemical Composition and Physical Properties of Wood and Nonwood Black Liquors during Heating, Ph.D. Thesis, Laboratory of Applied Chemistry, University of Jyväskylä, Jyväskylä, Finland. 
Maček, A. (1999): Research on combustion of black-liquor drops, Prog. Energy Combust. Sci., 25(3), 275-304.

Milanova, E. (1988): Variables affecting the swelling of kraft black liquor solids, J. Pulp Paper Sci., 14, 95-102.

Mosier, N., Wyman, C., Dale, B., Elander, R., Lee, Y.Y., Holtzapple, M. and Ladisch, M. (2005): Features of promising technologies for pretreatment of lignocellulosic biomass, Bioresour. Technol., 96(6), 673-686.

Noopila, T., Alén, R. and Hupa, M. (1991): Combustion properties of laboratory-made black liquors, J. Pulp Paper Sci., 17(4), 105-109.

Pakkanen, H. and Alén, R. (2012): Molecular mass distribution of lignin from the alkaline pulping of hardwood, softwood, and wheat straw, J. Wood Chem. Technol., 32(4), 279-293.

Sjöström, E., Janson, J., Haglund, P., Enström, B. (1965) The acidic groups in wood and pulp as measured by ion exchange. J. Polym. Sci. Part C. 11:221-241.

Swan, B. (1965): Isolation of acid-soluble lignin from the Klason lignin determination, Svensk Papperstidn, 68, 791-795.
Tunc, M.S. and van Heiningen, A.R.P. (2009): Autohydrolysis of mixed southern hardwoods: Effect of P-factor, Nord. Pulp Paper Res. J., 24(1), 46-51.

van Heiningen, A. (2006): Converting a kraft pulp mill into an integrated forest biorefinery, Pulp Paper Can., 107(6), 38-43.

Wayman, M. and Chua, M.G.S. (1979): Characterization of autohydrolysis aspen ( $P$. tremuloides) lignins. Part 4. Residual autohydrolysis lignin, Can. J. Chem., 57(19), 2612-2616.

Whitty, K., Backman, R., Forssén, M., Hupa, M., Rainio, J. and Sorvari, V. (1997): Liquor-to-liquor differences in combustion and gasification processes: Pyrolysis behaviour and char reactivity, J. Pulp Paper Sci., 23(3), 119-128.

Whitty, K., Backman, R. and Hupa, M. (2008): Influence of pressure on pyrolysis of black liquor: 1. Swelling, Bioresour. Technol., 99(3), 663-670.

Yoon, S.-H., Macewan, K. and van Heiningen, A.R.P. (2008): Hot-water pre-extraction from Loblolly pine (Pinus taeda) in an integrated forest products biorefinery, TAPPI J., 7(6), 27-32.

Manuscript received June 3, 2016 Accepted September 9, 2016

\section{Appendix}

\begin{tabular}{llrrrrrrrrrr}
\hline \multicolumn{1}{l}{ Table S1 - Content of the main compound groups in BLs (\% of total). } \\
\hline $\begin{array}{l}\text { Parameter/cooking } \\
\text { time (min) }\end{array}$ & & $\mathbf{3 0}$ & $\mathbf{6 0}$ & $\mathbf{9 0}$ & $\mathbf{1 2 0}$ & $\mathbf{1 5 0}$ & $\mathbf{3 0}$ & $\mathbf{6 0}$ & $\mathbf{9 0}$ & $\mathbf{1 2 0}$ & $\mathbf{1 5 0}$ \\
\hline \multirow{3}{*}{ Volatile acids } & Soda-AQ & 14.0 & 10.9 & 9.5 & 9.8 & 9.4 & 7.7 & 7.2 & 7.0 & 6.6 & 6.3 \\
& $\mathrm{O}_{2}-\mathrm{NaOH}$ & 19.2 & 17.7 & 17.3 & 15.8 & 15.2 & 16.4 & 14.4 & 12.5 & 12.8 & 11.5 \\
& Kraft & 12.7 & 10.7 & 9.9 & 10.0 & 9.9 & 9.3 & 8.0 & 7.1 & 6.9 & 6.9 \\
\cline { 2 - 12 } & Soda-AQ & 22.8 & 23.7 & 24.6 & 24.6 & 25.2 & 25.8 & 25.0 & 23.8 & 23.1 & 21.9 \\
Hydroxy acids & $\mathrm{O}_{2}-\mathrm{NaOH}$ & 27.8 & 25.2 & 25.6 & 25.5 & 26.0 & 30.1 & 25.3 & 25.1 & 23.8 & 23.7 \\
& Kraft & 30.8 & 26.2 & 24.7 & 24.8 & 24.4 & 31.5 & 27.6 & 24.6 & 24.8 & 24.3 \\
\cline { 2 - 12 } & Soda-AQ & 63.2 & 65.4 & 65.9 & 65.6 & 65.4 & 66.6 & 67.8 & 69.3 & 70.3 & 71.9 \\
Lignin & $\mathrm{O}_{2}-\mathrm{NaOH}$ & 53.0 & 57.1 & 57.0 & 58.7 & 58.7 & 53.5 & 60.3 & 62.4 & 63.5 & 64.8 \\
& Kraft & 56.5 & 63.1 & 65.4 & 65.2 & 65.7 & 59.2 & 64.4 & 68.4 & 68.3 & 68.8 \\
\cline { 2 - 11 } & Soda-AQ & 1.7 & 1.9 & 1.9 & 1.9 & 1.9 & 2.0 & 2.1 & 2.3 & 2.4 & 2.6 \\
Lignin-to-total acids & $\mathrm{O}_{2}-\mathrm{NaOH}$ & 1.1 & 1.3 & 1.3 & 1.4 & 1.4 & 1.2 & 1.5 & 1.7 & 1.7 & 1.8 \\
(ratio) & Kraft & 1.3 & 1.7 & 1.9 & 1.9 & 1.9 & 1.5 & 1.8 & 2.2 & 2.2 & 2.2 \\
\hline
\end{tabular}

a BLs obtained from the cooks with untreated (ref) and HW treated feedstocks. 
BIOREFINERY

Table S2 - The main organic composition of BLs (g/l). For abbreviations, see Table 2.

\begin{tabular}{|c|c|c|c|c|c|c|c|c|c|c|c|}
\hline \multirow{2}{*}{\multicolumn{2}{|c|}{ Component/cooking time, $\min$}} & \multicolumn{5}{|c|}{ Ref } & \multicolumn{5}{|c|}{ HW feedstocks } \\
\hline & & 30 & 60 & 90 & 120 & 150 & 30 & 60 & 90 & 120 & 150 \\
\hline & Soda-AQ & 9.5 & 8.5 & 8.0 & 8.3 & 8.3 & 6.4 & 6.6 & 6.6 & 6.8 & 6.9 \\
\hline \multirow[t]{3}{*}{ Total volatile acids } & $\mathrm{O}_{2}-\mathrm{NaOH}$ & 11.9 & 12.1 & 13.5 & 13.0 & 12.4 & 9.4 & 9.7 & 9.6 & 10.4 & 9.8 \\
\hline & Kraft & 8.9 & 8.7 & 9.0 & 9.3 & 9.4 & 7.4 & 7.3 & 7.2 & 7.3 & 7.4 \\
\hline & & 4.4 & 4.2 & 4.2 & 4.5 & 4.5 & 4.4 & 4.6 & 4.7 & 4.8 & 5.0 \\
\hline \multirow[t]{3}{*}{ Formic } & & 5.0 & 5.3 & 6.1 & 6.0 & 5.6 & 5.2 & 5.3 & 5.4 & 5.8 & 5.4 \\
\hline & & 4.5 & 4.5 & 4.9 & 5.2 & 5.3 & 5.4 & 5.5 & 5.4 & 5.6 & 5.7 \\
\hline & & 5.1 & 4.3 & 3.8 & 3.8 & 3.8 & 2.0 & 2.0 & 1.9 & 2.0 & 1.9 \\
\hline \multirow[t]{3}{*}{ Acetic } & & 6.9 & 6.8 & 7.4 & 7.0 & 6.8 & 4.2 & 4.4 & 4.2 & 4.6 & 4.4 \\
\hline & & 4.4 & 4.2 & 4.1 & 4.1 & 4.1 & 2.0 & 1.8 & 1.8 & 1.7 & 1.7 \\
\hline & Soda-AQ & 15.6 & 18.6 & 20.5 & 21.0 & 22.2 & 21.4 & 23.0 & 22.6 & 23.3 & 24.0 \\
\hline \multirow[t]{3}{*}{ Total hydroxy acids } & $\mathrm{O}_{2}-\mathrm{NaOH}$ & 17.2 & 17.3 & 20.0 & 21.0 & 21.2 & 17.3 & 17.1 & 19.2 & 19.4 & 20.3 \\
\hline & Kraft & 21.6 & 21.4 & 22.4 & 23.0 & 23.2 & 25.1 & 25.2 & 25.1 & 26.2 & 25.9 \\
\hline & & 1.7 & 2.2 & 2.5 & 2.6 & 2.8 & 1.8 & 2.3 & 2.3 & 2.5 & 2.7 \\
\hline \multirow[t]{3}{*}{ Glycolic } & & 1.7 & 1.7 & 1.9 & 2.1 & 2.2 & 2.1 & 2.1 & 2.3 & 2.3 & 2.4 \\
\hline & & 0.8 & 0.9 & 1.0 & 1.0 & 1.1 & 1.0 & 1.1 & 1.1 & 1.2 & 1.2 \\
\hline & & 2.0 & 2.6 & 3.1 & 3.2 & 3.5 & 2.9 & 3.5 & 3.5 & 3.7 & 4.0 \\
\hline \multirow[t]{3}{*}{ Lactic } & & 2.6 & 2.7 & 3.2 & 3.5 & 3.7 & 2.4 & 2.5 & 3.0 & 2.9 & 3.4 \\
\hline & & 2.7 & 2.8 & 3.2 & 3.1 & 3.2 & 3.4 & 3.7 & 3.9 & 4.0 & 3.8 \\
\hline & & 0.4 & 0.5 & 0.7 & 0.8 & 0.9 & 1.2 & 1.4 & 1.3 & 1.3 & 1.4 \\
\hline \multirow[t]{3}{*}{ 2-Hydroxybutanoic } & & 0.5 & 0.6 & 0.8 & 1.0 & 1.0 & 0.8 & 0.9 & 1.1 & 1.0 & 1.0 \\
\hline & & 0.6 & 0.7 & 0.8 & 0.9 & 0.9 & 1.5 & 1.6 & 1.6 & 1.7 & 1.7 \\
\hline & & 0.6 & 0.6 & 0.7 & 0.7 & 0.8 & 2.0 & 2.0 & 2.0 & 2.0 & 2.0 \\
\hline \multirow[t]{3}{*}{ Xyloisosaccharinic } & & 0.5 & 0.5 & 0.6 & 0.6 & 0.6 & 1.1 & 1.1 & 1.2 & 1.3 & 1.3 \\
\hline & & 0.7 & 0.7 & 0.7 & 0.7 & 0.7 & 2.3 & 2.2 & 2.1 & 2.2 & 2.2 \\
\hline & & 5.7 & 7.0 & 7.6 & 7.6 & 7.9 & 7.4 & 7.7 & 7.6 & 7.8 & 7.8 \\
\hline \multirow[t]{3}{*}{ Glucoisosaccharinic } & & 6.0 & 5.8 & 6.7 & 6.7 & 6.6 & 5.1 & 5.1 & 5.7 & 5.9 & 6.2 \\
\hline & & 10.1 & 9.9 & 9.7 & 10.2 & 10.1 & 9.4 & 9.1 & 8.9 & 9.4 & 9.5 \\
\hline & & 5.2 & 5.7 & 5.8 & 6.0 & 6.4 & 6.1 & 6.2 & 6.0 & 6.0 & 6.2 \\
\hline \multirow[t]{3}{*}{ Others a } & & 5.9 & 6.0 & 6.8 & 7.1 & 7.1 & 5.8 & 5.4 & 5.9 & 6.0 & 6.0 \\
\hline & & 6.7 & 6.4 & 7.0 & 7.1 & 7.2 & 7.5 & 7.5 & 7.5 & 7.7 & 7.5 \\
\hline & Soda-AQ & 43.2 & 51.3 & 54.8 & 55.8 & 57.8 & 55.2 & 62.3 & 65.8 & 71.1 & 78.9 \\
\hline \multirow[t]{3}{*}{ Lignin } & $\mathrm{O}_{2}-\mathrm{NaOH}$ & 32.8 & 39.2 & 44.5 & 48.4 & 47.8 & 30.8 & 40.8 & 47.8 & 51.8 & 55.4 \\
\hline & Kraft & 39.6 & 51.5 & 59.4 & 60.5 & 62.6 & 47.2 & 58.8 & 69.8 & 72.1 & 73.3 \\
\hline & Soda-AQ & 68.3 & 78.5 & 83.2 & 85.1 & 88.3 & 83.0 & 91.8 & 95.0 & 101.1 & 109.8 \\
\hline \multirow[t]{2}{*}{ Total } & $\mathrm{O}_{2}-\mathrm{NaOH}$ & 61.9 & 68.6 & 78.0 & 82.4 & 81.4 & 57.5 & 67.6 & 76.6 & 81.6 & 85.5 \\
\hline & Kraft & 70.1 & 81.6 & 90.8 & 92.8 & 95.2 & 79.7 & 91.3 & 102.1 & 105.6 & 106.6 \\
\hline
\end{tabular}

a Mainly 3,4-dideoxy-pentonic and 3-deoxy-pentonic acids. 